\title{
Partnership General Budget Support in Mozambique
}

\author{
Richard Carey
}

Director of the Development Cooperation Directorate, OECD

This is a summary of an extensive study prepared by a team of consultants and conducted in the framework of the Joint Evaluation of Budget Support 1994-2004 encompassing seven developing countries, under the auspices of a Steering Group, including the OECD's Development Assistance Committee.

\section{The Joint Evaluation of General Budget Support 1994-2004}

In 2004 a group of 17 donors and 7 partner governments commissioned a joint evaluation of General Budget Support(GBS). Its purpose was: to assess to what extent and under what circumstances GBS is relevant, efficient and effective for achieving sustainable impacts on poverty reduction and growth.

The outputs of the study are a Synthesis Report, and seven country studies, for Burkina Faso, Malawi, Mozambique, Nicaragua, Rwanda, Uganda, and Vietnam.

The Mozambique study was prepared by Richard Batley, Liv Bjomestad, Amelia Cumbi 


\section{Background:Recovering from Civil War}

From the beginning of the liberation war in 1964, Mozambicans experienced nearly 30 Years of violent strife, social and political disruption, and economic crisis. Under pressure of civil war, the infrastructure of governance disintegrated. In large parts of rural Mozambique, schools and health posts were destroyed and teachers and nurses evacuated. Around $37 \%$ of the population lost their homes, were displaced or became refugees.

Since the peace settlement in 1992, there ha been almost uninterrupted growth of around $8 \%$ per annum. This has reduced the level of absolute poverty from 69\% of the population n $1996-97$ to $54 \%$ in $2002-03$.

However, high rates of poverty, poor health indicators and high illiteracy rates persist. Mozambique's recovery was strongly supported by aid from bilateral and multilateral agencies. Official aid disbursements averaged about USD 1 billion a year from 1992-2004(about 30\% of Gross National Income)

\section{The Evolution of PGBS in Mozambique}

In the late 1990s, some longstanding bilateral donors saw a need for innovative and more coordinated support. Liberalisation of the economy and debt relief under the Heavily Indebted Poor Countries(HIPC) initiative made traditional forms of import support and balance of payments aid less relevant. Between 1996-2000 there was a trend towards pooling of aid sector level, but there was still concern that 'off-budget' aid-via individual projects or sector basket fundsseemed to undermine government systems and capacity.

Spurred by the HIPC initiative, Mozambique prepared a Poverty Reduction Strategy Paper(PRSP, known by its Portuguese acronym PARPA) in 2001, this provided a national strategy on which donors could align their aid.

Coordination of PGBS was agreed in 1999 and formalized in 2000 as a "common framework agreement" in a joint Donor Programme for Macro-Financial Support between the government and bilateral donors. An original group of six donors rapidly expanded to 10 in 
2002, 15 in 2004 and 17(the "G17") in 2005. The agreement required the government to prioritise poverty reduction according to the PRSP. While PGBS was the focus of the agreement, it also embraced other forms of programme aid, specifically sector support.

\section{Current Design of PGBS}

Difficulties with the original agreement-the unpredictable timing of disbursements, and conflicting donor interpretations of disbursement conditions-led to a new Memorandum of Understanding(MOU), signed in 2004 by 14 bilateral donors and the World Bank. Two more bilaterals joined in
2005. Observers include the African Development Bank(AfDB), the International Monetary Fund(IMF), Japan international Cooperation Agency(JICA), the United Nations(UN) and USAID.

The MOU clarified objectives and mechanisms of the partnership. An elaborate system of joint reviews timed to fit the governments budgetary cycle has been created, backed by an organisational structure of thematic and working groups. The review of government performance is matched by an annual review of donors' performance.

The 2004 agreement consolidated a redesign

\section{What is Partnership General Budget Support?}

- General Budget Support(GBS) is aid funding to government that is not earmarked to specific projects or expenditure items. It is disbursed though the governments' own financial management system. The finance is accompanied by other "inputs". conditions and procedures for dialogue, donor efforts to hannonise their aid and align it with notional policies and proceduies, and technical assistance and capacity building.

-In the late 1990s "new GBS" or "partnership GBS"(PGBS) emerged as a response to dissatisfaction with earlier aid instruments. "Partnership" is contrasted with the imposed conditionality of the structural adjustment era.PGBS is intended to support partner countries poverty reduction strategies. By channelling funds through national systems, it also aims to strengthen national planning and implementation capacity, increasing the effectiveness of all public expenditure, including aid. 
of the joint Programme that began in 2002. This better reflected government priorites and ownership of the process. The jointly agreed Performance Assessment Framework(PAF) drew policy actions and performance indicators from the government' s poverty reduction strategy and from line ministries' proposals for relevant sector indicators.

\section{Disbursements}

PGBS has grown from USD 30 million(3\% of official aid) in 2000, to USD 240 Million(19\% of official aid) by 2004(see Table 1)

\section{PGBS and Public Expenditures}

- PGBS has had a positive effect in increasing the proportion of public spending subject to the national budgetPGBS is the only aid that is fully 'onbudget' .
- Deficiencies in budget classifications and the scale of 'off-budget' aid mean that it is not always clear how funds are spent. However, reforms are improving investment budget execution, and reducing uncertainty about the real use of budgeted funds.

- Fiduciary risk, remains high, but government is committed to reform.

- Increasing allocation of budget funds to 'priority sectors' reflects the broader reform agenda and expanding resources, but PGBS has supported the government's commitment.

- PGBS has helped to increase the efficiency of public expenditure. For example, it has increased the proportion of recurrent expenditure available through the state budget, allowing it to correspond more directly to investment commitments. It has also made it easier for government to make its contributions to aid-founded projects.

Table 1:Partnership General Budget Support and Total Aid in Mozambique

\begin{tabular}{l|c|c|c|c|c|c|c|c|c|c|c}
\hline & 1994 & 1995 & 1996 & 1997 & 1998 & 1999 & 2000 & 2001 & 2002 & 2003 & 2004 \\
\hline Total ODA(actual)(USDm) & 1,255 & 1,275 & 957 & 959 & 1,107 & 1,647 & 1,096 & 993 & 2,330 & 1,092 & 1,289 \\
\hline $\begin{array}{l}\text { Total Partnership GBS } \\
\text { disbursements(USDm) }\end{array}$ & & & & & & & 30 & 88 & 101 & 154 & 239 \\
\hline PGBS as \% total ODA(\%) & & & & & & & $3 \%$ & $9 \%$ & $4 \%$ & $14 \%$ & $19 \%$ \\
\hline ODA as \% GN(\%) & $61 \%$ & $50 \%$ & $33 \%$ & $30 \%$ & $28 \%$ & $21 \%$ & $25 \%$ & $30 \%$ & $65 \%$ & $25 \%$ & $24 \%$ \\
\hline
\end{tabular}


- PGBS has reduced the cost of budget finance by making new and free sources of finance available to the budget.

- PGBS funds are becoming more predictable since donors agreed to make multi-annual commitments.

\section{PGBS Effects on Poverty and Growth}

Macroeconomic Performance Rapid economic growth preceded PGBS, and the policies that underpin a favourable macro-economic environment are not directly attributable to PGBS. PGBS donors support the macroeconomic policy dialogue led by the IMF.
PGBS has increased the resources available to the national budget and contributed to the transparency of public expenditure, but this has not yet resulted in improved fiscal discipline. (A banking crisis worsened fiscal discipline in two out of the five years that PGBS has been provided.) However, the fiscal deficit and instability would probably have been worse in the absence of PGBS.

\section{Poverty Reduction}

Between 1996/97 and 2002/03 there was a spectacular fall in the incidence of poverty (as measured by consumption) from $69 \%$ to $54 \%$ of the total population-an extraordinary

\section{Approach to the Evaluation}

- The evaluation was not intended to compare budget support with sector support or project aid. However, the evaluators found that there is not a sharp distinction between general and sector budget support, that many of the non-financial inputs to PGBS and other modalities are important in explaining its effects.

- The evaluation was based on a logical framework:this identified the inputs of PGBS and then traced its various possible effects from inputs to activities to output, outcomes and impacts.

- PGBS has been operating for only a few years, and it is often just one among a number of influences on outcomes and impacts. This makes it difficult to be certain about its long-term effects, but medium-term effects are clearer. The study set unusually rigorous standards for an aid evaluation, and applied the same methodology consistently across the seven countries.

- This was an independent evaluation. Its findings and recommendations are those of the evaluation team. 
reduction in six year. This easily reached the poverty reduction target set for the PRSP.

- PGBS has made a small contribution to the reduction of income poverty through its effect on macroeconomic stability and government spending.

- PGBS has had a modest effect in extending access to basic services in all the PRSP priority areas.

- Any PGBS effect on the empowerment and social inclusion of poor people is so for weak, and achieved indirectly through contributions to growth, employment, service delivery, anti-corruption measures and reform of the justice sector.

\section{Did PGBS change the level or composition of aid to Mozambique?}

The contribution of PGBS to the state budget increased substantially between 2000 and 2004. However, total aid did not increase over the same period. some donors (DFID, EC) increased both their aggregate aid and the proportion allocated to PGBS, but most donors have substituted PGBS for other modalities. Thus, at the national level PGBS has been a substitute for other aid flows, not additional.

\section{Institutional Effects of PGBS}

Planning and Budgeting Systems There are incremental, and do not relate well to planning documents. Approved budgets and actual expenditure are weakly linked. state budgets for recurrent costs are disconnected from investment funding by donors operating directly at sector or province level.

- PGBS has been influential both by bringing discretionary funds on budget and by focusing dialogue on the budget and shared policy objectives. (Bringing all types of donor funds on budget is an increasing priority for PGBS partners.)

- PGBS has strengthened reporting lines between core government and line ministries, and reduced direct line ministry-donor relationships. This has increased core governmental ownership of the budgetary process. However, the ownership may be undermined by the degree of donor involvement in the core policies and processes of government.

- Although domestic accountability remains weak, it is being strengthened through PGBS. 


\section{Policies and Policy Processes}

The Mozambique government is very centralised, and line ministries have a high degree of vertical control. Donor Influence is strong. Civil society participation in the policy process is limited. The availability of aid at sectoral and provincial level has reduced the need for strong policy formulation to attract funds within government.

- PGBS has begun to change this by bringing sector ministries into a wider policy debate which is more cross-sectoral, and somewhat more inclusive of civil society stakeholders.

- The PGBS agenda initially focused on the improvement of government systems, but since 2003 it has broadened to cover all aspects of government and donor policy relevant to the poverty reduction strategy.

- PGBS has added open and collective pressure to meet sector targets and carry out promised reforms.

Government Capacity and Capacity Building

Capacity in government is weak, and capacity development in core institutions of government (particularly the Ministry of Planning and Finance) has been fragmented, project-focused and largely delinked from PGBS.

Donors and government are now discussing a more coordinated programme. The most significant capacity building probably occurs as 'learning by doing'.

PGBS increases the resource envelope for decentralised funding, and is beginning to support decentralisation through dialogue and conditions.

\section{PGBS and Aid Effectiveness}

\section{Relevance}

The original design of PGBS was relevant to the national context. PGBS was built on analysis of earlier experience of programme aid, and on a thorough analysis of the economy and of government's managerial strengths and weaknesses. It led to the creation of a framework that has allowed PGBS to broaden its policy and poverty focus, and to increase government's participation. a highly coordinated and coherent structure for government-donor collaboration has been developed, providing a basis for governmentdonor agreement about priorities. The 
structure is inclusive of different aid modalities and different donors' perspectives on the speed of advance to PGBS. Such a partnership could not have emerged through project aid, and did not develop under structural adjustment programmes. There were earlier forms of donor-government collaboration, but none has been so institutionalised.

\section{Harmonisation and Alignment of Aid}

The broad pattern since 1994 has been for aid management to be concentrated in sector ministries, and then increasingly in the Ministry of Planning and Finance(MPF). Line ministries, particularly health, agriculture and education, continue to be important focuses of both sector and project aid, but sector support arrangements are increasingly being brought on-budget, and GBS is strengthening MPF's responsibility for financial management.

- The PRSP is the formal basis for longterm strategic alignment, and the G17 have now also aligned themselves to the government's own annual planning processes (the economic and social plan (PES) and PAF). This is a major advance in alignment.
- PGBS funds, review process and dialogue have elevated the status of the MPF as a focal point for national planning, and otherwise strengthened capacity for governmental systems and leadership

- The highly effective harmonisation and alignment mechanisms-the dialogue and shared conditions-developed by PGBS are unlikely to have occurred through any other aid instrument.

The high degree of harmonisation between the G17 donors could be of some concern for government, if all donors acted in concert to withhold aid. However, the catastrophic consequences of this possibility make it unlikely that such a situation would be allowed to develop.

\section{Quality of Partnership}

Ownership, in the sense of the strengthening of cross-sectoral national systems over which government exerts collective control has increased under PGBS with donorgovernment agreement on shared conditions and priority targets.

Transaction costs initially increased for government under PGBS, due to new dialogue 
requirements, new conditionalities, and unpredictable flows of funds. such costs spread to include MPF rather than shifting from line ministries. These costs may now be decreasing as government has adjusted and donors increasingly work through government systems. PGBS transaction costs will decrease as disbursement through the budget utilises government procedures, however the continuation of other aid modalities prevents significant reduction in line ministry aid management costs.

Interaction of aid modalities-PGBS dialogue has embraced other forms of aid (particularly sector support) and worked to strengthen complementarity between modalities within the framework of the budget and national policy. Off-budget aid remains very significant but PGBS donors (supported by financial sector reforms) are working to bring sector support on-budget and to improve to reporting of project aid to government.

\section{Unintended Effects of PGBS}

Bics against Private Sector Development?

PGBS has put little focus on improving the

\section{Cross-cutting issues}

- Generally, PGBS has given a practical impetus to cross-cutting issues already formally espoused within legislation.

-Women have strong formal rights and political representation. However, in the spheres of economic participation, access to service and justice, women and girls remain disadvantaged. An active gender working group is pursuing these issues within the joint Review process.

- Environment legislation is strong but practice is much weaker. PGBS and the joint Review have paid little attention to environmental matters.

- The HIV/ADIS prevalence rate is very high and increasing rapidly. HIV/ADIS had been dealt with as a matter for the health sector leading to an inadequate response to available funds for treatment and protection. The joint Review has pressed effectively for a cross-sectoral approach.

- Human rights are strongly established at a formal level, but less so in practice, particularly in regard to the performance of the courts, prisons and police. The joint Review has given collective impetus to the pursuit of legal and judicial reforms. 
business environment, except inasmuch as it strengthens the macro-economy, but it now gives some attention to this sector and these issues will be given greater prominence in the second PRSP.

\section{Undermining domestic revenue?}

The evaluation found no evidence that access to PGBS funds has reduced the mobilisation of domestic revenue.

\section{Undermining domestic accountability?}

The weaknesses of the budgetary and policy processes are also inhibitions on democratic accountability. Moreover, a large part of public expenditure is off-budget and therefore not subject to parliamentary scrutiny or external audit within Mozambique. The scope for parliamentary accountability has increased as the state budget has grown, and more donor funds have been brought within it. PGBS has shown that it is possible for donor and national accountability systems to reinforce each other.

Corruption has remained a problem but the Joint Review process is now pursuing the implementation of reforms. PGBS has made fiduciary risk a more central concern to donors, and has probably made corruption more discernible by involving donors nearer the core processes of government.

\section{Sustainability-Feedback and Learning}

PGBS has helped to build the sustainability of government systems, developed a sustained dialogue with government and has had a broadly positive impact on policy processes, macroeconomic management and service delivery.

The numerous, strong processes of shared learning between government and donors, with flexible mechanisms for adjusting to experience and maximising complementarities between different forms of aid, suggest a robust and sustainable partnership.

Learning processes have been extended to a widening group of stakebolders, including donors with different degrees of commitment to PGBS, sector ministries of government and non-government actors. However, the participation of the legislature and of civil society organisations remains weak. 


\section{Overall Conclusions}

This has been a very successful case of donor-government collaboration.

PGBS has contributed positively to conditions for economic growth and poverty reduction in
Mozambique. An important factor in explaining the success of PGBS, and other forms of aid, is the long-established relationship of trust between government and some core donors

The clearest and most direct effects of PGBS

\section{Recommendations}

\section{Aid strategy}

- Continue to bring more aid on budger, and develop a more explicit strategy to use different aid modalities according to their best fit

\section{Donor performance}

- continue to improve long and short term predictobility of disbursements

- Develop graduated responses to government performance

- Strengthen donor capacity to support policy analysis, planning and budgeting

- Minimise demands on senior officials' time

- Give government more space to develop its own growth and poverty reduction approach

\section{Government performance}

- Strengthen intra-government coordination

- Develop more coherent approaches to coherent approaches to capacity development

- Give more attention to policies and policy implementation for domestic revenue, the environment, HIV/AIDS and justice

- Strengthen measures against corruption

\section{Civil society}

- Strengthen the engagement of civil society in monitoring performance and holding government to account

\section{Privcte sector and growth}

- Pay more attention to private sector roles and strategies for pro-poor growth 
were seen in:

Harmonisation between a large number of partners and their increasing alignment on national systems.

PGBS' s increasing contribution to the proportion of public expenditure that goes through a growing state budget Strengthening planning and budgeting systems, policy processes, and macroeconomic performance.

Positive but generally slight and uncertain effect were discernible with regard to service delivery, to service responsiveness and access, to the reduction of income poverty and to the empowerment of poor people. This is not to say that the hypothesised causality links were false:PGBS design or the national response may have been inadequate, and/or PGBS effects may be outweighed by other factors. The main weaknesses in performance against the criteria adopted by the evaluation concerned:technical assistance and capacity building;predictability of funding (though this has improved since 2002); domestic accountability; and promotion of policies related to private sec색 development, and to the administration of justice and respect for human rights.

\section{Future Prospects}

PGBS appears to be a relatively efficient aid modality whose longer term effect is likely to be greater.

Recommendations focus on ways of strengthening both PGBS itself and the combined effectiveness of different aid modalities. 